\title{
CUATRO MUNDOS DEL HOMBRE: TIEMPO E HISTORIA ENTRE LOS CHAMULAS ${ }^{1}$
}

\author{
Gary H. Gossen \\ Universidad de \\ California-Santa Cruz
}

I. Es un lugar común creer que los pueblos tradicionales, es decir, los pueblos ágrafos como los indígenas de México, no tienen un concepto ni correcto ni objetivo de su propia historia. Este punto de vista predomina a través del espectro ideológico y político, y va desde ciertos historiadores conservadores, que opinan que mientras no tenga un pueblo una crónica escrita no puede contar con un registro adecuado de su historia, hasta los marxistas, que mantienen que los pueblos del "tercer mundo" no tienen conciencia histórica por no percibir su lamentable situación en el fluir del desarrollo universal de la historia. Así que resulta como una perogrullada de nuestro tiempo el decir que los pueblos ágrafos se encuentran fuera de la historia o inconscientes de la misma, pero, a mi juicio, este punto de vista es profundamente erróneo y dañino.

En el presente trabajo quisiera contradecir dicha perspectiva tan ampliamente acogida, presentando en forma de un bosquejo general el concepto chamula del tiempo y la historia. ${ }^{2}$ Quisiera demostrar

1 Este trabajo fue presentado originalmente en un simposio "La Civilización Indígena de Chiapas en el Mundo Contemporáneo", que se efectuó del 19 al 21 de agosto de 1974 en San Cristóbal de las Casas, Chiapas, como evento conmemorativo del V Centenario del Nacimiento de Fray Bartolomé de las Casas. Muchas personas me ayudaron con varios aspectos del presente artículo. Sobre todo quisiera brindar mi profundo agradecimiento a Victoria Refler Brcker, a Miguel León-Portilla, a Joseph Silverman y a Evon Z. Vogt, por haberme servido como fuentes de inspiración y crítica en mis investigaciones sobre la cultura chamula.

2 Hay, desde luego, varias excelentes investigaciones mexicanas que sirven de pauta y precedente a la mía. Desde las crónicas y códices escritos por los indígenas de la época de la conquista (véase El Códice Florentino de Bernardino de Sahagún y la gran serie de otros documentos etnohistóricos p.e., Hand- 
que los chamulas, como toda sociedad humana, gozan de conceptos del pasado muy útiles y vinculados con su experiencia retrospectiva y actual. Además, su historia se relaciona constantemente con el presente y se reafirma frente a las necesidades, esperanzas y amenazas de su vida actual. De manera que resulta ser, al fin y al cabo, como la nuestra, una historia subjetiva que los orienta y da sentido al mundo contemporáneo en que viven.

\section{Los cuatro mundos de los chamulas}

San Juan Chamula es un municipio indígena de 40,000 habitantes, ubicado en el Estado de Chiapas, en el extremo sur de México. Los chamulas son descendientes de los antiguos mayas y hablan el tzotzil, un idioma mayanse que también se habla en otras nueve comunidades indígenas de los altos de Chiapas. En suma, hay más de 100,000 personas que hablan el tzotzil. Los chamulas se dedican principalmente a la agricultura y a las artesanías populares de la región, como alfarería, talabartería y fabricación de carbón, muebles e instrumentos musicales. Viven dispersos en más de 100 parajes aislados que se encuentran en los valles y tierras montañosas de su territorio municipal. La cabecera, San Juan Chamula, sirve como centro ceremonial para la vida civil y religiosa. Estos aspectos públicos de su vida están regidos por más de 120 oficiales que toman cargos de un año de duración. Durante la tenencia de sus cargos ocupan casas en la cabecera, y después de cumplir con sus deberes ceremoniales y cívicos vuelven a trasladarse a sus parajes como "pasados". Entre los pueblos indígenas de Chiapas los chamulas se distinguen no sólo por ser los más numerosos, sino también por ser muy conservadores y, a veces, rebeldes en su mentalidad separatista. Por ejemplo, la Guerra de Castas de Chiapas, de 1868 a 1870, tuvo como centro dirigente a San Juan Chamula, y los personajes que sirvieron como líderes de esta rebelión eran chamulas.

Chamula ha sido una entidad cultural desde la época precolombina. ${ }^{3}$ Como heredero del patrimonio maya antiguo, Chamula ha con-

book of Middle American Indians, Tomos 12-14) y continuando con obras como las de Miguel León-Portilla (Tiempo y realidad en el pensamiento maya y Visión de los vencidos) y Ricardo Pozas Arciniega, cuyo Juan Pérez Jolote pretende reconstruir la autobiografía de un chamula que vivió en la época revolucionaria de este siglo; la tradición de la historia reportada desde el punto de vista indígena lleva un puesto de honor en las letras mexicanas.

3 Para quienes desean más información sobre Chamula, véanse Pozas, 1948 y 1959, y Gossen, 1974. 
servado a través de los siglos el concepto de múltiples creaciones del mundo y de sus habitantes. El ciclo cuadripartita, del cual vivimos actualmente en la cuarta, última y mejor etapa, es la obra maestra del Padre Sol, Nuestro Señor del Cielo, quien, según su creencia, es parigual a Jesucristo. Según esta perspectiva cosmológica, el Padre Sol circunscribe los límites del Universo y, a la vez, fija todos los ciclos temporales (días, años, y estaciones). El mismo Padre Sol estableció el orden en el mundo; esto lo hizo en varias etapas. Las primeras tres creaciones del Padre Sol resultaron fracasos porque los seres humanos hechos por él no se llevaron bien entre sí. Además tuvieron costumbres bárbaras como la de comer a sus hijos estando éstos bien gordos. De manera que el Padre Sol destruyó cada una de las tres primeras creaciones del mundo para hacer una más, la cuarta, que es la más reciente y en la que actualmente vivimos. Esta creación es la única que según el Padre Sol ha tenido éxito. ${ }^{4}$

Los cuatro mundos del Padre Sol comprenden la entidad temporal más grande que reconocen los chamulas. Aunque la entidad es propiamente cíclica, las cuatro partes pueden verse como secuencia lineal también, porque los sucesos de las más recientes creaciones no son meras repeticiones de las originales. Más bien las creaciones muestran un patrón de desarrollo acumulativo. Es decir, cada mundo, o creación, ha resultado cada vez mejor y más satisfactorio a juicio del Padre Sol. En este sentido, el ciclo de cuatro mundos comprende una totalidad que es más que la suma de las partes. Cada uno de los tres primeros lo destruyó el Creador, creyendo que su esfuerzo había resultado abortivo. Aunque los chamulas creen que la Cuarta Creación es el único "éxito" que ha experimentado la humanidad, también creen que este mundo está repleto de maldad y, por lo tanto, corre el riesgo de que el Padre Sol lo destruya tal como hizo con los anteriores. Así, ellos se ven obligados a defenderlo de los perversos y malvados que quieren fomentar la maldad y la corrupción.

Para los chamulas no importa saber a ciencia cierta cuántos años duró cada uno de los mundos, ni cuando se creó cada uno de ellos. Por ejemplo, en cuanto a la edad de la Primera Creación, varían las opiniones de los chamulas de 80,000 a 300 años. Dicen unos chamulas que la Cuarta Creación se efectuó hace unos 400 años. Otros dicen que no tiene más de 120 años de edad (que es el límite de la cuenta de generaciones -5 ó 6 - en su genealogía). Hay variación semejante para la posible edad de la Segunda y la Tercera Creaciones también.

\footnotetext{
4 Los chamulas no conservan en su tradición oral ninguna crónica que, como las nuestras, hacen destacar las maravillas de los antiguos mayas.
} 
Por eso, ni siquiera un promedio de las edades sugeridas por los informantes daría una cifra adecuada para la edad absoluta de las creaciones. Lo más importante del concepto es que las creaciones se siguen unas a otras como crónica del tiempo en la antigüedad.

La Primera Creación tiene sus orígenes en una triste oscuridad primitiva poblada de demonios, monos y (por influencia de los misioneros españoles) judíos. La Luna, Nuestra Madre del Cielo (sinónimo de la Virgen María) anda en la oscuridad y, de manera para ella desconocida, concibe. Luego, estando encinta, la persiguen los demonios, monos y judíos. Da a luz a un hijo. A éste lo matan los demonios y resucita en forma del Padre Sol, que durante dos días viaja hacia el poniente y baja desde el horizonte occidental al inframundo. Al tercer día sale en el este, amaneciendo así por primera vez. Así se le da la primera luz al mundo y se distingue la noche del día. El calor del Padre Sol, que sube al cenit al principio del cuarto día, mata a los demonios y con tal acción, crea el primer mundo. Después crea el relieve de la tierra y todas las formas de vida. De barro (o de palos en unas versiones) crea al primer hombre y a la primera mujer. Éstos, por bárbaros, echan a sus hijitos al agua hirviendo, pensando comérselos después. Por este horrible delito, el Padre Sol - con un castigo obviamente poético- destruye a la primera gente y al primer mundo con un diluvio de agua hirviendo. Así termina la Primera Creación.

La Segunda y Tercera Creaciones juntas comprenden una especie de edad heroica para los chamulas. Dos veces más el Padre Sol crea el mundo y todo lo que contiene. La gente de esta época trata en plan informal a los santos (hermanos menores del Padre Sol), al Padre Sol y a la Madre Luna, a otros seres sobrenaturales y también a animales antropomórficos. Lo pasan muy bien, con una que otra aventura o tragedia, cuyo resultado contribuye al repertorio de costumbres en que consiste la cultura chamula contemporánea. En esta época se crean las plantas de huerta y animales de corral; por ejemplo, se crean los frijoles del collar de la Madre Luna; las papas salen de la leche materna de la Madre Luna; los chiles se originan de la sangre del talón del Padre Sol; y lo más importante, el maíz, lo crea el Sol de un trozo de su propia ingle. En esta época todo el mundo habla español, pero al final de la tercera creación el español deja de ser el idioma universal, porque en dicha lengua, entendiéndose todo el mundo, se peleaban y discutían con gran facilidad. El Padre Sol decide que la vida humana resultaría más agradable para todos si se separaran los grupos de personas a base de diferentes lenguas, 
para que tuvieran paz. Así, se les da el idioma tzotzil a los chamulas, a fines del tercer mundo. Tras tanto esfuerzo por el Padre Sol en pro de la fecilidad humana, éste se enoja mucho cuando sigue habiendo tanta maldad y estupidez entre los humanos. Por lo tanto, manda que haya un tremendo terremoto que acaba con todo.

\section{Tiempo e historia en la Cuarta Creación}

El Padre Sol le concede a la humanidad una oportunidad más y vuelve a crear el mundo. Ésta es la Cuarta Creación, en la que actualmente vivimos. Según los chamulas, tendrá entre 150 y 400 años de edad.

Dentro de la Cuarta Creación, otros juegos de categorías temporales rigen y miden la experiencia humana. Por ejemplo, cada vida humana se organiza en etapas por medio de ritos de pasaje en tiempo del nacimiento, del bautizo, del matrimonio y de la muerte. Desde el nacimiento hasta el bautizo (un mes a 2 años) al niño se le dice mono (mash) porque no tiene nombre. Este tocayo se explica por el vínculo simbólico que tiene un niño no bautizado con los monos que habitaban la tierra antes de salir por primera vez el Padre Sol para crear el mundo y la cultura humana. Los monos se dedicaban a hábitos bárbaros, como el de comer a sus propios hijitos, a los que todavía no se les había puesto nombres, estando bien gordos éstos en la juventud. Por lo tanto, poner el nombre en el rito del bautizo tiene mucho significado temporal porque así se acerca el niño más al comportamiento social normativo. De manera parecida, desde el bautizo hasta la muerte, cada vida humana simboliza el progreso de los antiguos, de los primeros mundos hacia el presente. En otras palabras, las etapas de la ontogenia, es decir, el desarrollo de cada vida humana, recrea simbólicamente la filogenia, las etapas de la evolución humana, según se representa ésta en la mitología. Dicha perspectiva nos ayuda a comprender por qué en la sociedad chamula se respeta tanto a los ancianos; es porque llevan consigo, siendo mayores, todo el conocimiento y sabiduría acumulados de la experiencia humana.

Aunque estiman mucho a los ancianos y a los antepasados, la memoria genealógica es poco profunda, no llegando a más de cinco generaciones en las familias más poderosas. De manera que un anciano suele acordarse de sucesos históricos de su propia vida, digamos desde hace 60 u 80 años, y de sucesos ajenos desde unos 40 ó 60 años más en el pasado que se le han contado de la época de sus 
abuelos y tatarabuelos. Esta suma, 120 a 150 años, parece ser el máximo de profundidad a que llega su memoria genealógica e histórica. A pesar de esto, sí se conservan crónicas y archivos de tasas vitales en el centro ceremonial de Chamula, pero estos datos (apuntados según el calendario gregoriano) le son desconocidos a la gran mayoría de los chamulas y no influyen en la conducta de su vida cotidiana en lo más mínimo. La crónica de la Cuarta Creación, pues, se cuenta a base de generaciones de familias y a base de sucesos naturales y humanos de importancia para ellos.

El porvenir es importante en cuanto a las listas de cargos civiles y religiosos que desean tener los hombres. Hacen constar su compromiso de desempeñar estos papeles rituales hasta con 15 años de anticipación. También hablan del porvenir con algo de pesimismo a causa de la posible destrucción total de la Cuarta Creación en el año 2000. Pero aunque unos chamulas no dejan de pensar en dicha fecha ominosa, siempre es asunto más bien cíclico que lineal.

La manera más común de referirse a la crónica de la Cuarta Creación no es a base de unidades como años o fechas, sino a base de grandes momentos históricos cuya posición cronológica relativa la sabe la mayoría de adultos. Pero como ya se ha dicho, esta serie de grandes momentos, o puntos de referencia, no se remonta más allá de 150 años. Los chamulas no tienen por qué hablar de nada más allá de esta "frontera" cronológica, siendo ya de otra época, diferente a la de la Tercera Creación. Los grandes momentos de referencia en la Cuarta Creación tienen relación cronológica bastante fija y predecible para la mayoría de los chamulas con quienes trabajé. Las fechas que van incluidas en la siguiente lista no son importantes para ellos. Las incluyo sólo para facilitar la orientación del lector. Lo que sí les importa es el orden relativo de los sucesos.

- El tiempo del Padre Miguel Hidalgo (yora pale mikel), 18121825, las Guerras de Independencia.

- El tiempo de la guerra de Pedro Díaz Cuzcat, o el tiempo de Galindo (yora leto yu? un kuskat o yora leto yu? un kalinto), 1865 1869, un movimiento nativista, con enfoque geográfico en Chamula; efectivamente es la extensión chiapaneca de las Guerras de Castas de Yucatán.

- El tiempo de la ceniza (yora tan), 1902, la erupción y caída de ceniza de un volcán cerca de Tapachula.

- El tiempo de la guerra de Pajarito (yora leto yu?un paharito), 1910-1911, una rebelión chamula y un conflicto civil que ocurrie- 
ron cuando, alentados por el obispo de San Cristóbal, los chamulas se opusieron al gobierno de la capital del estado, Tuxtla Gutiérrez.

- El tiempo de la guerra de Carranza (yora leto yu?un karansa), 1911-1920, la Revolución Mexicana.

- El tiempo de la fiebre (yora $k^{\prime} a k^{\prime} a l$ čamel), 1918, la epidemia de influenza de 1918.

- El tiempo de la iglesia cerrada (yora makbil č́ulna), 1934-1936, la época de política anticlerical que alcanzó su máxima expresión bajo el régimen del Presidente Lázaro Cárdenas; en esta época la organización religiosa de Chamula funcionó clandestinamente.

- El tiempo cuando ya no gobernaban los ancianos (yora č́abal ša moletik ta kavilto), 1937-1941, por orden de la oficina de Asuntos Indígenas de San Cristóbal, se obligó a los chamulas a que se nombraran para los cargos políticos a quienes fueran jóvenes, tuvieran conocimiento del castellano y una actitud de cooperación con los oficiales de San Cristóbal y Tuxtla Gutiérrez.

- El tiempo cuando se construyó el camino a Tuxtla (yora melçah be ta tušta), la construcción de la sección de la carretera panamericana entre San Cristóbal y Tuxtla Gutiérrez, la capital del Estado. Muchos chamulas trabajaron en esta obra.

Los sucesos más recientes, desde 1950, todavía no se han cernido por la tradición para usarse como "mojones" históricos generales. Una sequía de los principios de los años 60 , por ejemplo, puede llegar a ser un gran momento en la historia chamula, pero todavía no se sabe esto con absoluta seguridad. También es probable que la exploración petrolera de los últimos 5 años se recuerde como punto de referencia para la época contemporánea.

\section{Otras unidades del tiempo cíclico}

Los chamulas se refieren constantemente a otras unidades de tiempo, siendo éste para ellos casi una obsesión como lo era para los antiguos mayas. El ciclo temporal de más importancia (además del gran ciclo de cuatro mundos) que sobrevive en Chamula desde la antigüedad maya es el calendario solar (365 días) de diez y ocho meses de veinte días cada uno, más un mes de 5 días sobrantes. Los chamulas lo ven como ciclo natural comprendido por la oscilación de las aparentes posiciones de la salida y la puesta del Sol, desde el extremo sur en el día 26 de diciembre hasta el extremo norte (verano) y de vuelta al extremo sur. Sin embargo, el calendario chamula no parece tomar en cuenta el día sobrante que hay que agregar cada 
cuatro años al calendario solar para que salga con toda exactitud. Este calendario lo utilizan los chamulas como base de su horario agrícola anual, que señala los días de buen agüero para la quiebra, la siembra, las limpias y la cosecha. También se pueden nombrar fechas de los días festivos según el antiguo calendario solar, pero éstos suelen calcularse todos los años a base principalmente del calendario católico ("Galván"), que utilizan los oficiales civiles y religiosos.

Existe una forma gráfica del calendario antiguo, pero no he visto más que un solo ejemplar. Consiste en una tabla de madera muy dispareja y burda, de $30 \mathrm{~cm}$. por $70 \mathrm{~cm}$. y $1 \mathrm{~cm}$. de grueso. Parece haberse hecho de un trozo de una puerta vieja que ya no servía. En la casa chamula de la que salió, estaba colgado el calendario de un clavo al pie de una sencilla plataforma de madera que les servía de cama a los habitantes. Los días se cuenta por medio de una mancha vertical de carbón que se le pone diariamente a la superficie lisa del calendario. Al fin de cada serie de 20 manchas, que comprenden un mes, se hace más gruesa la vigésima mancha. Esta mancha gruesa sugiere simbólicamente que los días - concebidos espacialmente- se acumulan a lo largo del mes. Es análogo este concepto al de los antiguos dioses mayas que cargaban el peso del tiempo durante sus ciclos respectivos. La metáfora del tiempo acumulado como cargo o peso se hace más clara aún por el hecho de que al calendario chamula se le pone otra capa más de carbón todos los días, todos los meses y todos los años, aumentando así su "peso".

El calendario católico se usa para calcular las fechas de las fiestas anuales. Un almanaque, llamado "El Calendario del más antiguo Galván", lo utilizan los oficiales y escribanos para ordenar el año ceremonial. Aunque muchos saben las fechas de las fiestas según los meses del antiguo calendario maya, éste no les sirve para calcular las fiestas. La única actividad ritual que todavía se rigen por cálculos sacados del calendario antiguo es la de cambiar las ofrendas de flores en los altares de los oficiales. Esto debe de celebrarse al principio de todos los meses (18) de 20 días. Con esta sola excepción, es el calendario católico el que sirve de base a la organización del año ritual.

El calendario de las fiestas es una fuente muy importante de orientación para los chamulas. La mayoría de los adultos puede referirse a cualquier día específico o a una temporada general, precisando el número de días antes de una fiesta, durante ésta o después de ella. (Por ejemplo, nuestra fecha 28 de junio probablemente se traduciría más fácilmente al tzotzil como "cuatro días después de la fiesta de San Juan"). La razón por la que les sirven las fiestas de orientación 
temporal general radica en el hecho de que las fiestas son los puntos cumbres de recreo para los laicos y también las ocasiones de máximo gasto de energía de parte de los oficiales religiosos.

Otra fuente de orientación temporal es el cambio de las estaciones. El contraste más notable en los altos de Chiapas es la diferencia entre la temporada seca y la lluviosa. La primera comienza en noviembre y dura hasta abril; la segunda, desde mayo hasta octubre, con el llamado "veranillo de San Juan" en julio y agosto.

Muchos otros ciclos se utilizan para aludir al tiempo. El ciclo del cultivo de maíz, por ejemplo, proporciona más de diez términos temporales que en realidad son frases descriptivas de las etapas progresivas de la temporada agrícola; p.e., "tiempo de elotes tiernos" corresponde al periodo entre mediados de agosto hasta mediados de septiembre. Otros ocho términos se refieren a las etapas de la Luna. Los chamulas también reconocen el movimiento regular de las varias constelaciones y planetas en los cielos nocturnos.

\section{La dinámica del tiempo y de la historia}

Por lo antes expuesto se puede ver que los chamulas, como sus antepasados mayas, tienen su pensamiento y cultura articulados por una serie de ciclos temporales. Para ellos son útiles, prácticos y, por su referente solar, muchos también son sagrados. De sus categorías temporales no se cuentan muchas que correspondan exactamente a las nuestras. Entre las características de su visión histórica y temporal destaca el aspecto cíclico, en que todo lo que ocurre tiene lugar dentro del marco de patrones ya establecidos que volverán a suceder. Pero a la vez, de manera casi paradójica, las necesidades e intereses del presente acondicionan y reforman constantemente el contenido del pasado. Así que presente y pasado se relacionan según patrones de feedback lógico. El amanecer diario - tiempo presente- no es más que una reiteración del primer momento del primer mundo - tiempo pasado.

No sólo aspectos de la naturaleza sino también sucesos humanos muestran este aspecto "telescópico" de su visión histórica. Una anécdota personal puede servir de ejemplo. Los chamulas solían dirigirnos a mi esposa y a mí la pregunta siguiente: $-i$ Se muerden y se comen las personas en su país?- Medio confundidos y sorprendidos, solíamos contestar - iClaro que no! ¿Tienen Uds. tales costumbres?Se reían a carcajadas por nuestra respuesta ridícula y contestaban a veces - Pues no, pero esto hacía la primera gente-. Tras muchos 
intercambios de este tipo, logré desentrañar el sentido tras lo aparentemente absurdo. Supe que, según su perspectiva geográfica, los Estados Unidos (slumal hrinko) se ubicaban en los lejanos extremos desconocidos de la tierra. Por lo tanto era lógico para ellos que siendo sumamente raros nosotros, deberíamos provenir de donde todavía no habían avanzado los pueblos más allá del nivel bárbaro (p.e., el infanticidio y la antropofagia) de las primeras creaciones del hombre. En otras palabras, veían las costumbres humanas "decentes" en escala deslizante, disminuyéndose cada vez más, tanto en el eje temporal como en el eje espacial, según la distancia que caminaba uno fuera de Chamula. Así que lo lejano y lo extraño son, desde su perspectiva, primitivos también. Además, teniendo facciones europeas y ojos claros, nos preguntaban a menudo si teníamos demonios o santos como parientes, ya que lo sagrado, lo peligroso y dañino se relacionan con marcadas diferencias sociales y niveles históricos primitivos.

De manera semejante los chamulas creen que los ladinos son sobrevivientes de la Tercera Creación, época en la que todos hablaban español y se peleaban entre sí. Luego fueron separados los pueblos por el Padre Sol para evitar que hubiera discusiones y guerras. Los chamulas, hablando tzotzil, creen que han progresado más allá de aquella etapa, mientras que los ladinos se han quedado atrás por el hecho de que todavía hablan español. También se identifica a los ladinos con tendencias belicosas y pendencieras, tal como las tenían los habitantes de la Tercera Creación. Nuevamente vemos un vínculo lógico en la historia chamula entre los papeles de los grupos sociales en el presente y los correspondientes papeles y costumbres de los grupos en el pasado.

Tal enlace no conduce exclusivamente a opiniones negativas en cuanto a grupos no chamulas. Por ejemplo, un ladino, el llorado Don Erasto Urbina de San Cristóbal de las Casas, era una persona tan humanitaria en su trato con la comunidad indígena, que los chamulas le han concedido en su tradición oral un papel mítico. Debido en parte a su propia ascendencia indígena y a su gran bondad, lo han hecho una especie de santo. En unos relatos lo identifican como ayudante contemporáneo y amigo de San Cristóbal, junto a quien intervino para impedir que los carrancistas destruyeran la iglesia de San Cristóbal durante la época de la Revolución. En otros relatos orales, dicen los chamulas que fue Don Erasto quien logró acabar el conflicto revolucionario en Chiapas mediante un avión que mandó traer de México. Según el relato, el General Obregón vino acompañado de Don Erasto en el avión y juntos corrieron a los carrancistas. Estos relatos 
llaman nuestra atención de dos maneras. Primeramente, a Don Erasto le han asignado hazañas revolucionarias que no figuran en las historias mexicanas. En segundo lugar, Don Erasto era, culturalmente, un ladino; sin embargo ha surgido como héroe de la comunidad indígena. Esto es raro, ya que los ladinos son vistos por los chamulas como pobres sobrevivientes salvajes de la época de la Tercera Creación. A pesar de tal identificación tanto les impresionó Urbina con su bondad y justicia, que lo relacionan con los santos cuyas épocas principales fueron las dos primeras creaciones del hombre. Así que tiempo presente y tiempo pasado se relacionan para facilitar su concepción de lo bueno y lo malo en la vida humana. Es una perspectiva histórica que no puede juzgarse como correcta o no correcta, sino como subjetivamente útil o no.

\section{Conclusión}

Quisiera terminar este comentario subrayando el hecho de que la perspectiva indígena sobre el pasado tiene importancia crucial para una nación como México, que ha llegado a destacarse entre los países modernos por sus valiosos esfuerzos de fomentar el respeto y conocimiento de sus minorías étnicas y culturales. Está claro que México, como país multi-énico, no puede menos de reconocer que tiene una pluralidad de historias, cada una de las cuales le proporciona sentido a su correspondiente sociedad y una perspectiva útil sobre su situación existencial. Los chamulas no se encuentran fuera de la historia, ni tampoco es ingenua o incorrecta su visión histórica.

Partiendo de este punto de vista, quisiera terminar mi comentario con unas sugerencias generales que parecen surgir naturalmente de los datos chamulas. Si como extranjero me permiten esta libertad, quisiera hacer hincapié en la necesidad de integrar la perspectiva indígena del pasado a los programas de enseñanza de la historia mexicana tanto aquí como en otros países de América y de ultramar. Los mexicanos gozan de una ideología revolucionaria que hará mucho más fácil tal integración a las materias pedagógicas, como lo ha sido para otros países, inclusive los Estados Unidos, en donde las distintas perspectivas de las minorías étnicas van integrándose a los libros de texto sobre la historia americana con lamentable lentitud. También convendría tener en cuenta que todo programa de cambio cultural dirigido por el gobierno mexicano hacia la comunidad indígena tendrá que implementarse dándose cuenta de que el concepto del cambio cultural, hasta el valor del cambio, es diferente desde la perspectiva 
indígena a lo que significa para la mayoría mestiza y occidental. Los chamulas no se sienten inferiores y, cosa rara, somos nosotros a quienes nos juzgan atrasados y bárbaros en muchos sentidos importantes. Nos urge tener en cuenta tal concepción axiológica, tal visión de nuestra propia realidad histórica.

Tengo la sensación de que el gran humanista Fray Bartolomé de las Casas, a quien rendimos homenaje en estos días, aprobaría la tentativa que he hecho de proporcionar a las visiones indígenas de su propio pasado el respeto y la atención que merecen. El darnos cuenta de que ahora mismo no estamos sólo a fines de agosto de 1977 en el año de Jesucristo, sino también en el tiempo de los elotes tiernos en la Cuarta Creación del Padre Sol, es ser más sabios, más ricos y profundos en cuanto a la comprensión humana, y mejor capacitados para comunicarnos respetuosa y benéficamente con quienes tienen diferentes premisas básicas acerca del mundo.

\section{REFERENCIAS}

Gossen, Gary H.

1974 Chamulas in the World of the Sun: Time and Space in a Maya Oral Tradition. Cambridge, Massachusetts.

León-Portilla, Miguel

1968 Tiempo y realidad en el pensamiento maya. Prólogo de J. Eric.

S. Thompson, Apéndice de Alfonso Villa Rojas, UNAM, Instituto de Investigaciones Históricas, México (Serie de Culturas Mesoamericanas, 2).

1969 Visión de los vencidos: relaciones indígenas de la Conquista, Introducción, selección y notas, 4a. ed., UNAM, México (Biblioteca del Estudiante Universitario, 81).

Pozas Arciniega, Ricardo

1948 Juan Pérez Jolote, México.

1959 Chamula: un pueblo indio de los altos de Chiapas. Memorias

Sahagún, Bernardino de del Instituto Nacional Indigenista, VIII, México.

1957 The Florentine Codex: General History of the Things of New Spain. Trad. A. J. O. Anderson and C. E. Dibble, New Mexico, Santa Fe.

Wauchope, Robert and Howard F. Gline

1972-75 Guide to Ethnohistorical Sources. Handbook of Middle American Indias. Vols. 12-13, Austin, Texas. 